\title{
Application of Starch-Stabilized Silver Nanoparticles as a Colorimetric Sensor for Mercury(II) in 0.005 mol/L Nitric Acid
}

\author{
Penka Vasileva, ${ }^{1}$ Teodora Alexandrova, ${ }^{1}$ and Irina Karadjova ${ }^{2}$ \\ ${ }^{1}$ Department of General and Inorganic Chemistry, Faculty of Chemistry and Pharmacy, Laboratory of Nanoparticle Science \\ and Technology, University of Sofia "St. Kliment Ohridski", 1 J. Bourchier Blvd., 1164 Sofia, Bulgaria \\ ${ }^{2}$ Department of Analytical Chemistry, Faculty of Chemistry and Pharmacy, University of Sofia "St. Kliment Ohridski", \\ 1 J. Bourchier Blvd., 1164 Sofia, Bulgaria \\ Correspondence should be addressed to Penka Vasileva; pvasileva@chem.uni-sofia.bg
}

Received 12 December 2016; Revised 13 March 2017; Accepted 28 March 2017; Published 13 April 2017

Academic Editor: Roberto Comparelli

Copyright (C) 2017 Penka Vasileva et al. This is an open access article distributed under the Creative Commons Attribution License, which permits unrestricted use, distribution, and reproduction in any medium, provided the original work is properly cited.

\begin{abstract}
A sensitive and selective $\mathrm{Hg}^{2+}$ optical sensor has been developed based on the redox interaction of $\mathrm{Hg}^{2+}$ with starch-coated silver nanoparticles (AgNPs) in the presence of $0.005 \mathrm{~mol} \mathrm{~L}^{-1} \mathrm{HNO}_{3}$. The relative intensity of the localized surface plasmon absorption band of AgNPs at $406 \mathrm{~nm}$ is linearly dependent on the concentration of $\mathrm{Hg}^{2+}$ with positive slope for the concentration range $0-12.5 \mu \mathrm{g} \mathrm{L}^{-1}$ and negative slope for the concentration range $25-500 \mu \mathrm{g} \mathrm{L}^{-1}$. Experiments performed demonstrated that metal ions $\left(\mathrm{Na}^{+}, \mathrm{K}^{+}, \mathrm{Mg}^{2+}, \mathrm{Ca}^{2+}, \mathrm{Pb}^{2+}, \mathrm{Cu}^{2+}, \mathrm{Zn}^{2+}, \mathrm{Cd}^{2+}, \mathrm{Fe}^{3+}, \mathrm{Co}^{2+}\right.$, and $\left.\mathrm{Ni}^{2+}\right)$ do not interfere under the same conditions, due to the absence of oxidative activity of these ions, which guarantees the high selectivity of the proposed optical sensor towards $\mathrm{Hg}^{2+}$. The limits of detection and quantification were found to be $0.9 \mu \mathrm{g} \mathrm{L}{ }^{-1}$ and $2.7 \mu \mathrm{g} \mathrm{L}^{-1}$, respectively, and relative standard deviations varied in the range $9-12 \%$ for $\mathrm{Hg}$ content from 0.9 to $12.5 \mu \mathrm{g} \mathrm{L}^{-1}$ and $5-9 \%$ for $\mathrm{Hg}$ levels from 25 to $500 \mu \mathrm{g} \mathrm{L} \mathrm{L}^{-1}$. The method was validated by analysis of CRM Estuarine Water BCR505. A possible mechanism of interaction between AgNPs and $\mathrm{Hg}^{2+}$ for both concentration ranges was proposed on the basis of UV-Vis, TEM, and SAED analyses.
\end{abstract}

\section{Introduction}

Monitoring of toxic metals in aquatic ecosystems is an important analytical task as far as these contaminants adversely affect the environment and have serious medical effects on human health. One of the most harmful pollutants among them is $\mathrm{Hg}$, which is still released in the environment and widely distributed in air, water, and soil [1]. At very low concentrations, $\mathrm{Hg}$ affects human's health, causing a variety of diseases to the heart, kidneys, brain, and nervous and endocrine systems [2] Naturally occurring levels of mercury in groundwater and surface water are less than $0.5 \mu \mathrm{g} \mathrm{L}{ }^{-1}$, although local mineral deposits may produce higher levels in groundwaters. Essential quality standard for $\mathrm{Hg}$ maximum permissible limit of $1 \mu \mathrm{g} \mathrm{L} \mathrm{L}^{-1}$ has been adopted at EU level and requires regular monitoring of $\mathrm{Hg}$ content in drinking waters. It is well known that $\mathrm{Hg}$ exists in natural waters as different species: $\mathrm{Hg}^{0}$, methyl-Hg, and inorganic $\mathrm{Hg}(\mathrm{II})$; however, the dominant toxic species in drinking waters is $\mathrm{Hg}(\mathrm{II})$. Various instrumental methods and techniques have been developed for $\mathrm{Hg}$ determination at low environmentally relevant concentrations like atomic absorption/emission spectrometry (AAS/AES) [3], atomic fluorescence spectrometry (AFS) [4, 5], and high-performance liquid chromatography (HPLC) $[6,7]$. In spite of being very sensitive and precise for $\mathrm{Hg}$ determination, these methods often require a time-consuming sample preparation step as well as expensive instrumentation. Various colorimetric assays (based on the use of sensitive chromophores or fluorophores [8-11], polymers [12, 13], oligonucleotides [14, 15], DNA [16, 17], and metal nanoparticles [18-20]) have been developed and reported in the literature as convenient and simple alternative methods for the detection of target analytes without the requirement of sophisticated apparatus.

Metal nanoparticles have unique properties and applications in numerous fields, which are attributed to the collective dipole oscillation known as Surface Plasmon Resonance (SPR) [21]. This phenomenon makes them very desirable 
for colorimetric sensing of $\mathrm{Hg}^{2+}$ ions because the interaction between the nanoparticles and the analyte changes the intensity and/or position of the absorption band in the visible spectrum, which often might be observed with the naked eye [22]. The limitations observed for these systems are mainly connected with poor selectivity, high detection limit for $\mathrm{Hg}(\mathrm{II})$, complicated synthesis of the probe materials, or complicated analytical procedures.

In this study, we present a new colorimetric assay for $\mathrm{Hg}^{2+}$ ions in $0.005 \mathrm{~mol} \mathrm{~L}^{-1} \mathrm{HNO}_{3}$ using starch-stabilized silver nanoparticles (AgNPs). A change in the absorbance strength is expected as a result of the redox interaction between AgNPs and either $\mathrm{Hg}^{2+}$ ions or $\mathrm{NO}_{3}{ }^{-}$ions. The $\mathrm{Hg}$ concentration determines which of these two redox reactions dominates as the two oxidants compete with each other for Ag oxidation. This way, detection of very low environmentally relevant $\mathrm{Hg}$ contents is possible. Several sensing systems have been already reported based on the interaction between AgNPs and $\mathrm{Hg}$ (II) ions [23-32]; however, detailed study of $\mathrm{Hg}$ behavior in the presence of another competitive oxidant is rarely performed and discussed. A dual functional sensor for determination of $\mathrm{Hg}$ and $\mathrm{H}_{2} \mathrm{O}_{2}$ has been developed based on a similar approach: addition of $\mathrm{H}_{2} \mathrm{O}_{2}$ to a mixture of AgNPs and $\mathrm{Hg}$ (II) ions [33]. The method presented in this study, however, differs not only as a mechanism of the process, but also as a behavior of $\mathrm{Hg}^{2+}$ ions at very low concentrations (below $25 \mu \mathrm{g} \mathrm{L}^{-1}$ ) towards AgNPs in the presence of $\mathrm{NO}_{3}{ }^{-}$ions as a second oxidant. A simple and fast analytical procedure for determination of $\mathrm{Hg}$ in drinking waters is developed and verified by the analysis of a certified reference material.

\section{Materials and Methods}

2.1. Apparatus. UV-Vis absorption spectra were recorded on an Evolution 300 spectrometer (Thermo Scientific, USA) within the 200-800 $\mathrm{nm}$ range using quartz cuvettes with $1 \mathrm{~cm}$ optical path length. High-purity water was used as a reference sample for background absorption. The morphology and particle sizes were examined using a high-resolution transmission electron microscope (TEM, JEOL JEM-2100 operating at an accelerating voltage of $200 \mathrm{kV}$ ). A volume of $5 \mu \mathrm{L}$ AgNPs suspension was placed on a carbon-covered copper grid for TEM and air-dried. The histogram of AgNPs size distribution and the mean diameter of nanoparticles were determined by counting at least 200 nanoparticles from the different TEM images using ImageJ software. Some structural details of the nanoparticles were analyzed using the high-resolution TEM image and SAED pattern. The zeta $(\zeta)$ potential of nanoparticles was measured with a ZetaSizer Nano ZS (Malvern) instrument.

2.2. Chemicals. All chemicals used were of analytical-reagent grade and all aqueous solutions were prepared in high-purity water (Millipore Corp., Milford, MA, USA). Silver nitrate $\left(\mathrm{AgNO}_{3}, 99.8 \%\right)$, soluble starch, sodium hydroxide $(\mathrm{NaOH}$, $99 \%)$, nitric acid $\left(\mathrm{HNO}_{3}, 65 \%\right)$, salts of the different cations studied $\left(\mathrm{NaCl}, \mathrm{KCl}, \mathrm{MgCl}_{2}, \mathrm{CaCl}_{2}, \mathrm{~Pb}\left(\mathrm{NO}_{3}\right)_{2}, \mathrm{ZnCl}_{2}, \mathrm{CuCl}_{2}\right.$,
$\mathrm{NiCl}_{2}, \mathrm{CdCl}_{2}, \mathrm{CoCl}_{2}$, and $\mathrm{FeCl}_{3}$ ) (from Merck, Germany), and pharmaceutical grade D-(+) glucose (from Alfa Aesar, Germany) were used. Stock $\mathrm{Hg}$ standard solution, Trace $\mathrm{CEPT}^{\mathrm{TM}}, 998 \mu \mathrm{g} \mathrm{mL}^{-1}$ in $2 \mathrm{~mol} \mathrm{~L}^{-1} \mathrm{HNO}_{3}$ (Sigma-Aldrich, USA), was used to prepare a working standard solution of $1000 \mu \mathrm{g} \mathrm{L}^{-1} \mathrm{Hg}^{2+}$ in $0.01 \mathrm{~mol} \mathrm{~L}^{-1} \mathrm{HNO}_{3}$. Standard solutions for $\mathrm{Hg}$ within the concentration range of $0-1000 \mu \mathrm{gL}^{-1}$ were prepared weekly by serial dilution of this solution in $0.01 \mathrm{~mol} \mathrm{~L}^{-1} \mathrm{HNO}_{3}$. All diluted $\mathrm{Hg}$ solutions were stored in dark glass flasks and kept refrigerated at $4^{\circ} \mathrm{C}$.

2.3. Synthesis and Characterization of Silver Nanoparticles. The synthesis of AgNPs follows a green synthetic procedure as described in our previous study [34]. The silver nanoparticles were obtained through a reduction reaction of silver nitrate with $\mathrm{D}$-glucose as a reducing agent in the presence of starch as a stabilizer and suitable sodium hydroxide amount as a reaction catalyst. Briefly, $24 \mathrm{~mL}$ of $0.001 \mathrm{M} \mathrm{AgNO}_{3}$ and $48 \mathrm{~mL}$ of $0.2 \%$ solution of starch were mixed and left for at least 15 minutes to form a complex under an ultrasonic treatment (ultrasonic bath, power $100 \mathrm{~W}$, frequency $38 \mathrm{MHz}$ ). After that, $720 \mu \mathrm{L}$ of $0.1 \mathrm{M} \mathrm{D}$-glucose was added and sonicated for 5 minutes. The reaction was started by the addition of $3.6 \mathrm{~mL}$ of $0.1 \mathrm{M} \mathrm{NaOH}$ and continued for one hour at a constant temperature $\left(30^{\circ} \mathrm{C}\right)$ in an ultrasonic bath to ensure the homogeneous formation of the silver nanoparticles.

The as-prepared AgNPs were purified and concentrated three times by ultracentrifugation ( $90 \mathrm{~min}, 14,000 \mathrm{rpm}$ ). The dispersion obtained was denoted as a stock solution of AgNPs and used in the experiments for colorimetric determination of $\mathrm{Hg}^{2+}$. The AgNPs stock solution was kept in a dark glass flask at room temperature and was homogenized in an ultrasonic bath for $30 \mathrm{~min}$ prior to each experiment.

2.4. Colorimetric Detection of $\mathrm{Hg}^{2+}$ Ions. The colorimetric detection of $\mathrm{Hg}^{2+}$ ions via starch-stabilized silver nanoparticles was conducted as follows: an aliquot of $200 \mu \mathrm{L}$ AgNPs stock solution and $300 \mu \mathrm{L}$ high-purity water were consecutively added to a small quartz cuvette, followed by addition of $500 \mu \mathrm{L} \mathrm{Hg}^{2+}$ solution with varying concentrations. The resulting mixture was equilibrated by stirring on Vortex for an optimum incubation time and then the UV-Vis spectrum in the wavelength range of $200-800 \mathrm{~nm}$ was recorded. In order to investigate the sensitivity of the colorimetric assay towards other ions, starch-stabilized AgNPs were allowed to interact under the same conditions with $50 \mu \mathrm{mol} \mathrm{L}^{-1}$ solutions of alkali $\left(\mathrm{Na}^{+}, \mathrm{K}^{+}\right)$, alkaline earth $\left(\mathrm{Mg}^{2+}, \mathrm{Ca}^{2+}\right), \mathrm{Pb}^{2+}$, and transition-metal ions $\left(\mathrm{Cu}^{2+}, \mathrm{Zn}^{2+}, \mathrm{Cd}^{2+}, \mathrm{Fe}^{3+}, \mathrm{Co}^{2+}\right.$, and $\mathrm{Ni}^{2+}$ ) (separately for each ion). The resulting solutions were monitored by optical absorption spectroscopy.

2.5. Determination of $\mathrm{Hg}$ in Tap/Underground Water. Tap/ underground water sample $(20 \mathrm{~mL})$ was filtered through a $0.45 \mu \mathrm{m}$ filter and acidified with $\mathrm{HNO}_{3}$ until reaching $\mathrm{pH}$ in the range 2-2.3. Sample aliquot of $500 \mu \mathrm{L}$ was transferred to a quartz cuvette, and $200 \mu \mathrm{L}$ stock solution of AgNPs was added and the mixture was stirred by the Vortex. After the incubation time of $5 \mathrm{~min}$, the UV-Vis absorbance was 


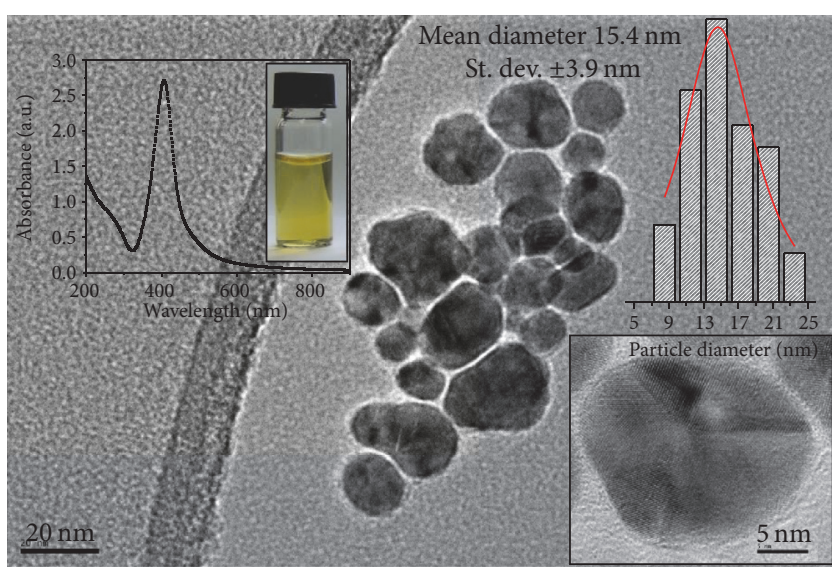

FIGURE 1: TEM image of starch-stabilized silver nanoparticles; insets: UV-Vis absorption spectrum and digital photographs (left), high-resolution TEM image of single nanoparticles, and histogram of nanoparticle size distribution (right).

measured at $407 \mathrm{~nm}$. Parallel sample aliquot of $250 \mu \mathrm{L}$ is diluted twice with $0.005 \mathrm{~mol} \mathrm{~L}^{-1} \mathrm{HNO}_{3}$ and passed through the procedure described above. The response of this sample (increase or decrease, related to the original one, Figure 4) is used to distinguish the low from the high linear concentration range of $\mathrm{Hg}$ and to choose an appropriate calibration curve.

\section{Results and Discussion}

3.1. Characterization of AgNPs. The UV-Vis absorption spectrum of starch-stabilized AgNPs, recorded at $25^{\circ} \mathrm{C}$, is shown in Figure 1 (inset). A single and sharp SPR band appears at $407 \mathrm{~nm}$, which indicates the formation of nanometer-sized particles. This is further confirmed by the TEM observation and size distribution histogram, shown in Figure 1.

The spherical-like AgNPs exhibit a relatively narrow size distribution with a mean diameter of $15.4 \pm 3.9 \mathrm{~nm}$. In addition to the nanospheres, some typical polyhedral nanoparticles (multiple twined nanocrystals) can be easily observed. The crystalline nature of AgNPs is clearly observed on the HRTEM image in Figure 1 (inset) and proved by the lattice characterization (e.g., the spacing between the individual lattice fringes of $0.235 \mathrm{~nm}$, which corresponds to (111) plane lattice spacing of pure silver). The colloidal stability of starch-coated AgNPs is confirmed by the $\zeta$-potential value of $-25.3 \pm 1.3 \mathrm{mV}$ measured in $0.001 \mathrm{~mol} \mathrm{~L}^{-1} \mathrm{KCl}$ at $\mathrm{pH} 6.8$.

3.2. The Optimization of Colorimetric Sensing of $\mathrm{Hg}^{2+}$. Several parameters were investigated systematically in order to establish optimal conditions for the direct colorimetric detection of $\mathrm{Hg}^{2+}$. As a first step, the $\mathrm{pH}$ value was adjusted taking into account the analysis of real samples and $\mathrm{HNO}_{3}$ which is typically used for water sample preservation. The experiments performed showed that $0.005 \mathrm{~mol} \mathrm{~L}^{-1} \mathrm{HNO}_{3}$ ensured the highest sensitivity and could be accepted as an optimal sample medium. In order to evaluate the optimum contact time, the kinetic of interaction between AgNPs and
$\mathrm{Hg}^{2+}$ in the presence of $0.005 \mathrm{~mol} \mathrm{~L}^{-1}$ nitric acid was followed within one hour by measurements of UV-Vis absorbance. Typical evolution of UV-Vis absorbance spectrum with time, due to the interaction of AgNPs with $400 \mu \mathrm{g} \mathrm{L}^{-1} \mathrm{Hg}^{2+}$ and respective color change of the AgNPs dispersion, is shown in Figure 2.

The changes that occurred in the LSPR absorption band of AgNPs are reflected on the color of the samples, which can be seen even with the naked eye. It is seen that the sensor's response is significant during the first five minutes of the reaction process and a negligible change in the absorption intensity is observed over time. This fact allows convenient analytical detection of $\mathrm{Hg}^{2+}$ within only five minutes.

As a next step, the sensitivity and applicability of starchcoated AgNPs for quantitative determination of $\mathrm{Hg}^{2+}$ ions under the defined optimal conditions were studied. The colorimetric response and LSPR band behavior were monitored as a function of $\mathrm{Hg}^{2+}$ concentrations, ranging from 0 to $500 \mu \mathrm{g} \mathrm{L}^{-1}$ in the presence of $0.005 \mathrm{~mol} \mathrm{~L}^{-1} \mathrm{HNO}_{3}$ (Figure 3).

As seen from the UV-Vis absorbance spectra (5-minute incubation time), the addition of $0.005 \mathrm{~mol} \mathrm{~L}^{-1} \mathrm{HNO}_{3}$ results in a considerable decrease of the intensity of AgNPs characteristic plasmon band at $407 \mathrm{~nm}$ accompanied by a slight blue shift (Figure 3(a)). In addition, a shoulder band appears at the wavelength range of $450-600 \mathrm{~nm}$. The increase of $\mathrm{Hg}^{2+}$ concentration from 0 to $12.5 \mu \mathrm{g} \mathrm{L}^{-1}$ in $0.005 \mathrm{~mol} \mathrm{~L}^{-1} \mathrm{HNO}_{3}$ leads to a gradual increase of the intensity of the characteristic plasmon band of AgNPs at $407 \mathrm{~nm}$ and its value gradually approximates to the absorption intensity of the blank nanoparticle solution (without both $\mathrm{NO}_{3}{ }^{-}$and $\mathrm{Hg}^{2+}$ ). In addition, the intensity of the shoulder band decreases along with increasing intensity of the main plasmon absorbance band. The spectra show a clear isosbestic point at $445 \mathrm{~nm}$ upon addition of $\mathrm{Hg}^{2+}$ in $0.005 \mathrm{~mol} \mathrm{~L}^{-1} \mathrm{HNO}_{3}$, demonstrating that the aggregation of AgNPs is directly related to the concentration of $\mathrm{Hg}^{2+}$. Contrariwise, a gradual decrease of the intensity of the characteristic plasmon band of the AgNPs at $407 \mathrm{~nm}$ is observed for the $\mathrm{Hg}$ concentration range from 25 to $500 \mu \mathrm{g} \mathrm{L}^{-1}$. The spectra presented in Figure 3(b) also show that the decrease of intensity of the absorbance maximum at $407 \mathrm{~nm}$ is accompanied with a slight blue shift, which is strengthened for the higher concentrations of $\mathrm{Hg}^{2+}$. This phenomenon is already reported and described as a change of the refractive index of the particles and the formation of a mercury layer around AgNPs, yielding an amalgam-like structure $[25,35,36]$. It might be suggested that, for the first $\mathrm{Hg}$ concentration range $\left(0-12.5 \mu \mathrm{g} \mathrm{L}^{-1}\right)$, a redox reaction proceeds between zero-valent silver $\left(\mathrm{Ag}^{0}\right)$ and either $\mathrm{Hg}^{2+}$ or $\mathrm{NO}_{3}{ }^{-}$ions. The values of standard electrode potentials of the components in the system confirm this suggestion: $E_{0}\left(\mathrm{Ag}^{+} / \mathrm{Ag}^{0}\right)=0.799 \mathrm{~V} ; E_{0}\left(\mathrm{Hg}^{2+} / \mathrm{Hg}^{0}\right)=0.854 \mathrm{~V}$; $E_{0}\left(\mathrm{NO}_{3}{ }^{-} / \mathrm{NH}_{4}{ }^{+}\right)=0.864 \mathrm{~V}$. Because the standard electrode potential of $\mathrm{NO}_{3}{ }^{-} / \mathrm{NH}_{4}{ }^{+}$is commeasurable with that of $\mathrm{Hg}^{2+} / \mathrm{Hg}^{0}$, two competitive oxidizing agents are involved in the studied sensing system. The most probable explanation for the decrease of LSPR band intensity in the presence of $0.005 \mathrm{~mol} \mathrm{~L}^{-1} \mathrm{HNO}_{3}$ and further increase upon addition of 


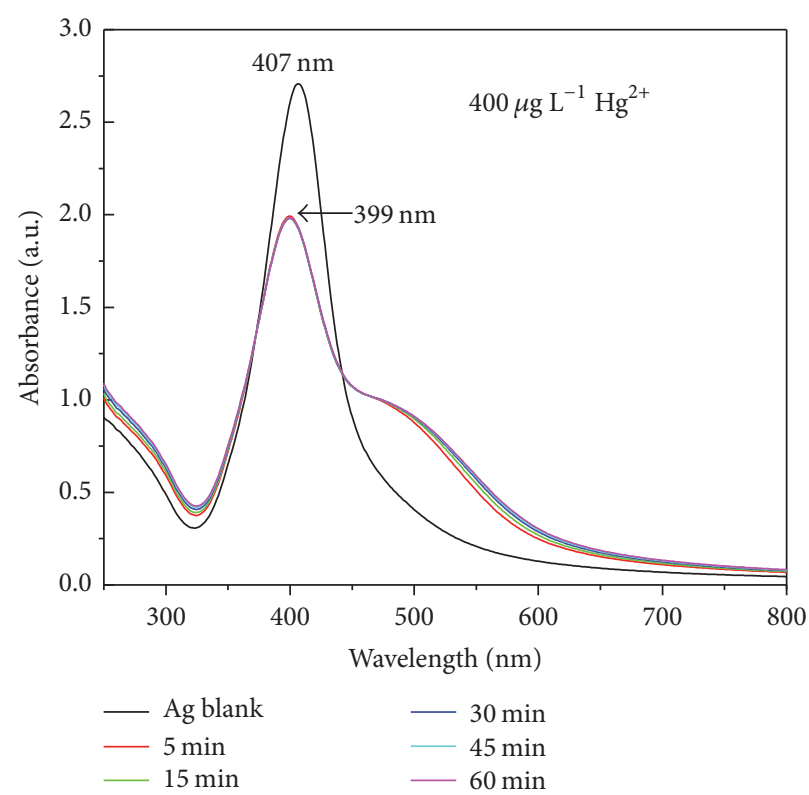

(a)

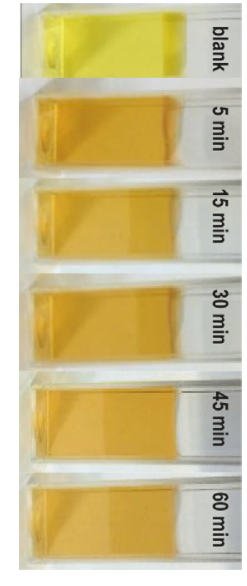

(b)

Figure 2: (a) Evolution of UV-Vis absorbance spectrum of AgNPs and (b) color change of the AgNPs dispersion upon the addition of $400 \mu \mathrm{g} \mathrm{L}^{-1} \mathrm{Hg}^{2+}$ in the presence of $0.005 \mathrm{~mol} \mathrm{~L}^{-1} \mathrm{HNO}_{3}$.

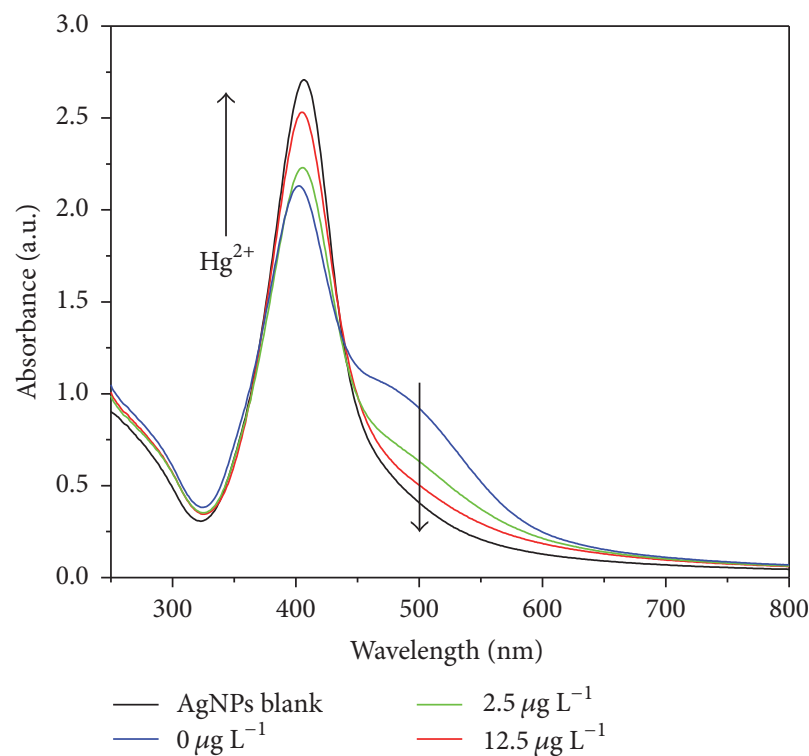

(a)
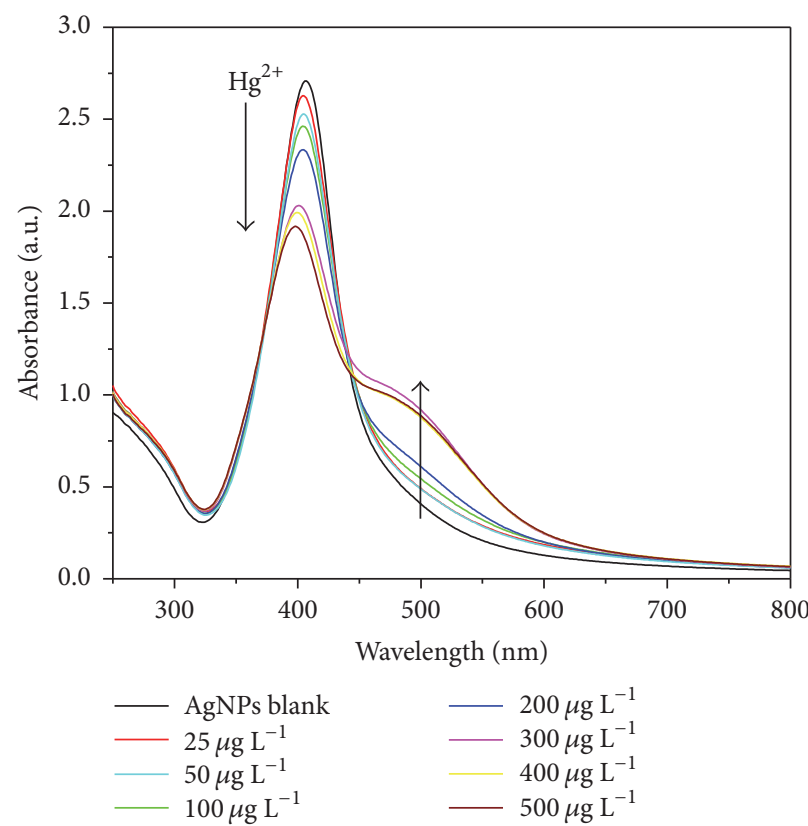

(b)

FIGURE 3: UV-Vis absorption responses of starch-stabilized AgNPs recorded 5 min after the addition of $\mathrm{Hg}^{2+}$ with various concentrations: (a) $0-12.5 \mu \mathrm{g} \mathrm{L}^{-1} \mathrm{Hg}^{2+}$ and (b) $25-500 \mu \mathrm{g} \mathrm{L}^{-1} \mathrm{Hg}^{2+}$ in the presence of $0.005 \mathrm{~mol} \mathrm{~L}^{-1} \mathrm{HNO}_{3}$.

$\mathrm{Hg}^{2+}$ (Figure 3(a)) is that, at low $\mathrm{Hg}^{2+}$ concentrations, the oxidative effect of $\mathrm{NO}_{3}{ }^{-}$ions towards surface silver atoms is dominant. In the presence of higher concentrations of $\mathrm{Hg}^{2+}$ (Figure 3(b)), the surface of nanoparticles is protected by the layer of Ag-Hg-amalgam due to the sorption and reduction of positively charged $\mathrm{Hg}^{2+}$ on the surface of negatively charged AgNPs followed by amalgamation. In this way, the surface of AgNPs is inaccessible for oxidation by $\mathrm{NO}_{3}{ }^{-}$. Evidently, within the range of $25-500 \mu \mathrm{g} \mathrm{L}^{-1} \mathrm{Hg}^{2+}$, the main redox interaction is between the AgNPs and $\mathrm{Hg}^{2+}$. Such 


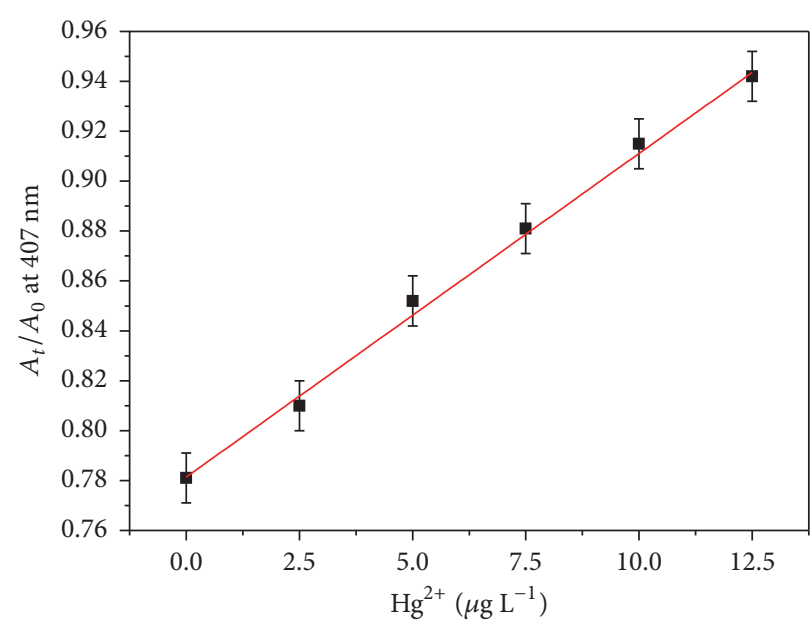

- Experimental data

- Linear fit

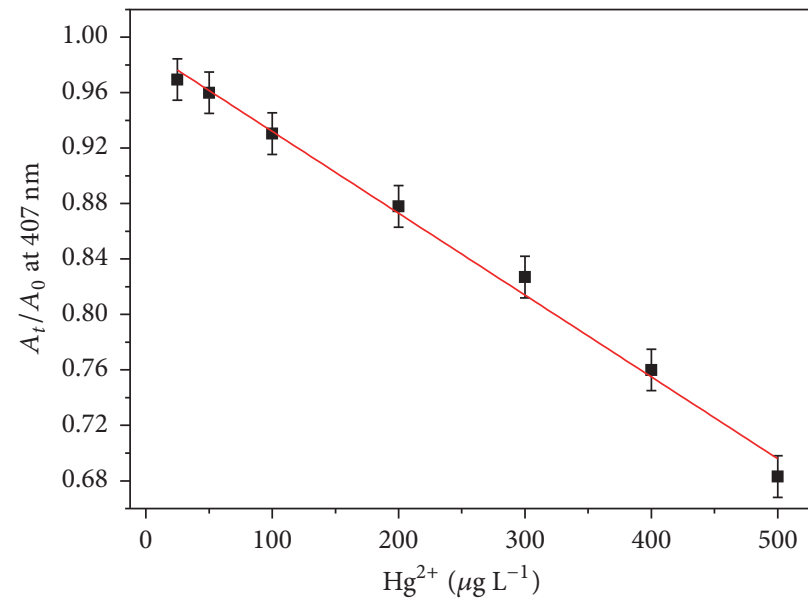

- Experimental data

— Linear fit

(a)

(b)

FIGURE 4: Plot of $A_{t} / A_{0}$ as a function of the $\mathrm{Hg}^{2+}$ concentration over the ranges of (a) $0-12.5 \mu \mathrm{g} \mathrm{L} \mathrm{L}^{-1}$ and (b) $25-500 \mu \mathrm{g} \mathrm{L} \mathrm{L}^{-1}$ in the presence of $0.005 \mathrm{~mol} \mathrm{~L}^{-1} \mathrm{HNO}_{3}$.

behavioral dissimilarities of the analyte $\left(\mathrm{Hg}^{2+}\right)$ for different concentration ranges have not been observed and reported in the previous studies on the AgNPs-based optical sensing system for $\mathrm{Hg}^{2+}$ colorimetric detection. We have to point out, however, that none of these reports mention the acidity of the reaction media, which most probably determines the oxidizing power of reagents in the system.

For quantitative determination of $\mathrm{Hg}^{2+}$, the change of the intensity of LSPR band maximum of silver nanoparticles at $407 \mathrm{~nm}$ upon the addition of analyte with various concentrations was estimated as a ratio $A_{t} / A_{0}$, where $A_{0}$ corresponds to the intensity of the absorbance maximum of blank AgNPs solution (without both $\mathrm{NO}_{3}{ }^{-}$and $\mathrm{Hg}^{2+}$ ions) and $A_{t}$ corresponds to the intensity of the absorbance maximum of silver nanoparticles $5 \mathrm{~min}$ after the addition of $\mathrm{Hg}^{2+}$ standard solutions (Figure 4).

As indicated in Figures 4(a) and 4(b), linear correlations exist between the relative value of the absorbance maximum intensity and the concentration of $\mathrm{Hg}^{2+}$ over the concentration ranges $0-12.5 \mu \mathrm{g} \mathrm{L}^{-1}\left(\mathbf{A}=0.7814+1.30 \times 10^{-2} \mathbf{c}\right.$ with $\left.R^{2}=0.995\right)$ and $25-500 \mu \mathrm{g} \mathrm{L}^{-1}\left(\mathbf{A}=0.991-5.90 \times 10^{-4} \mathbf{c}\right.$ with $R^{2}=0.993$ ), respectively. As a conclusion, the optical sensor studied using starch-stabilized AgNPs ensures a linear response over the concentration range from 0.9 to $12.5 \mu \mathrm{g} \mathrm{L}^{-1}$ which covers all environmentally relevant concentrations of $\mathrm{Hg}$ and might be used for fast screening of $\mathrm{Hg}$ in the aquatic environment. The second concentration range from 25 to $500 \mu \mathrm{g} \mathrm{L}^{-1} \mathrm{Hg}^{2+}$ can be successfully applied for the determination of $\mathrm{Hg}$ in highly contaminated and rarely found industrial wastewaters.

3.3. Selectivity of $\mathrm{Hg}^{2+}$ Optical Sensing by Starch-Coated AgNPs. From an analytical point of view, it is very important

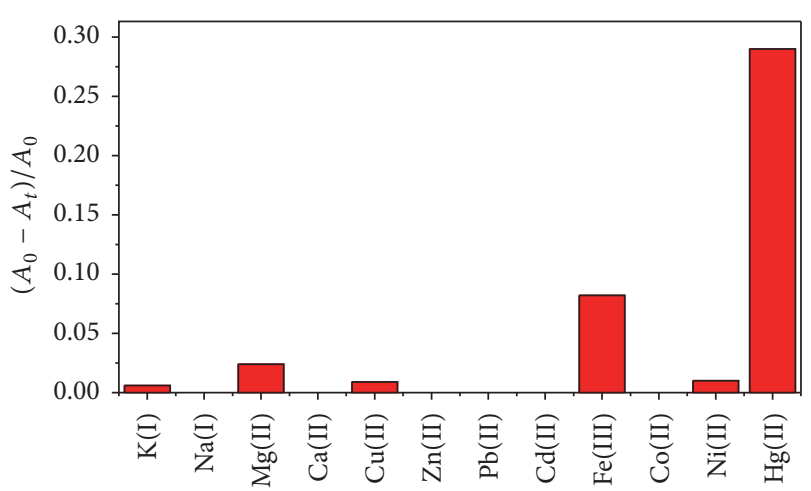

FIGURE 5: Colorimetric response of starch-stabilized AgNPs recorded $5 \mathrm{~min}$ after the addition of $5 \times 10^{-5} \mathrm{~mol} \mathrm{~L}^{-1}$ metal ions.

to define the selectivity of the proposed system for colorimetric $\mathrm{Hg}^{2+}$ determination. This has been evaluated through the response of the assay to various environmentally relevant metal ions including $\mathrm{Na}^{+}, \mathrm{K}^{+}, \mathrm{Mg}^{2+}, \mathrm{Ca}^{2+}, \mathrm{Pb}^{2+}, \mathrm{Cu}^{2+}, \mathrm{Zn}^{2+}$, $\mathrm{Cd}^{2+}, \mathrm{Fe}^{3+}, \mathrm{Co}^{2+}$, and $\mathrm{Ni}^{2+}$ under the same conditions as in the case of $\mathrm{Hg}^{2+}$. The optical response of AgNPs to the tested ions (concentration level of $50 \mu \mathrm{mol} \mathrm{L}^{-1}$ ) after $5 \mathrm{~min}$ of their addition (separately for each ion) is illustrated in Figure 5. For comparison, the optical response of AgNPs to the $\mathrm{Hg}^{2+}$ ions at a concentration level of $2.5 \mu \mathrm{mol} \mathrm{L}^{-1}$ is also presented.

It is easy to observe that all other metal ions produce a much weaker signal (almost at baseline level) except $\mathrm{Fe}^{3+}$ which shows modest interference. The reason is that only $\mathrm{Hg}^{2+}$ can be reduced by surface atoms of AgNPs to form stable $\mathrm{Ag}-\mathrm{Hg}$ amalgam. The addition of $\mathrm{Fe}^{3+}$ resulted in a tiny intensity decrease and red shift of the absorption band. This 


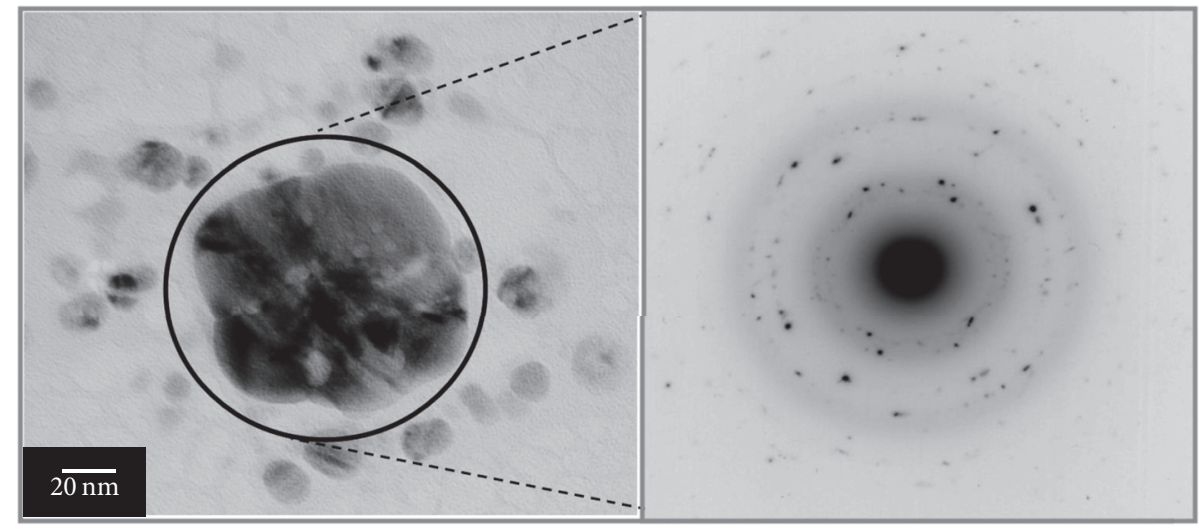

(a)

(b)

FIGURE 6: (a) TEM image (scale bar is $20 \mathrm{~nm}$ ) and (b) corresponding SAED pattern of starch-coated silver nanoparticles after treatment by $\mathrm{Hg}^{2+}$ solution at a concentration of $500 \mu \mathrm{g} \mathrm{L}^{-1}$ in the presence of $0.005 \mathrm{~mol} \mathrm{~L}^{-1} \mathrm{HNO}_{3}$.

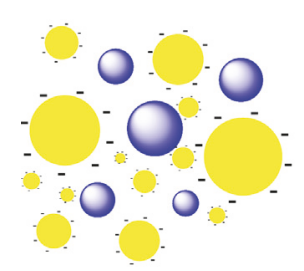

Metal bridging force

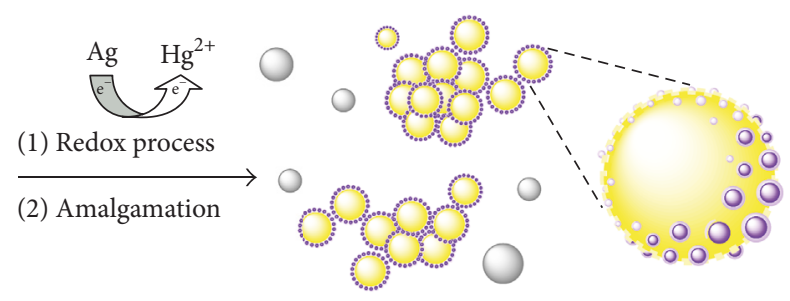

Aggregation

$$
\begin{array}{ll}
\mathrm{Hg}^{2+} \text { ions } & \bigcirc \mathrm{Ag}^{+} \text {ions } \\
\text { AgNPs } & \circ \mathrm{Ag}_{n} \mathrm{Hg}_{m} \text { or/and mercury atoms }
\end{array}
$$

FIGURE 7: The proposed mechanism of the interaction between starch-coated AgNPs and $\mathrm{Hg}^{2+}$ solution.

effect could be interpreted in terms of Fe(III) complexation with oxidized species of carbohydrates (starch and glucose) which are sorbed on the surface of silver nanoparticles [37].

3.4. Mechanism of Interaction between $\mathrm{AgNPs}$ and $\mathrm{Hg}^{2+}$. To elucidate the mechanism of sensing activity of the starchcoated AgNPs towards $\mathrm{Hg}^{2+}$, the nanoparticles were examined before and after $\mathrm{Hg}^{2+}$ exposure using TEM with SAED observations. Figure 6 shows TEM micrograph with the corresponding SAED pattern obtained from the agglomerate formed during interaction of AgNPs with $\mathrm{Hg}^{2+}$ solution at a concentration of $500 \mu \mathrm{g} \mathrm{L}^{-1}$.

As can be seen from Figure 6(a), the nanoparticles are of varying sizes and there is a large distribution after $\mathrm{Hg}^{2+}$ exposure. The TEM image shows a larger particle, which is surrounded by smaller particles. It seems that larger particles are undergoing Ostwald ripening. A similar observation is already reported for gold nanoparticles utilized for mercury removal from drinking water [38] and for colorimetric detection of $\mathrm{Hg}^{2+}$ using the AgNPs embedded in cyclodextrinsilicate composite [39].

The data from the analysis of SAED pattern (Figure 6(b)) are summarized with interpretation accuracy of $1 \%$ in Table 1. The analysis shows the existence of $\mathrm{Ag}_{2} \mathrm{Hg}_{3}$ amalgam (PDF
65-3156) and Ag (PDF 89-3722) as main phases in the aggregated mass formed during the interaction of starchcoated AgNPs with $\mathrm{Hg}^{2+}$. Some impurities of metallic $\mathrm{Hg}$ (PDF 01-1017) are also detected.

On the basis of TEM/SAED results, a multistep interaction of $\mathrm{Hg}^{2+}$ with the silver nanoparticles could be inferred. The interaction involves (i) the electrostatic attraction between negatively charged silver nanoparticles and positively charged $\mathrm{Hg}^{2+}$ species, decreasing the distance between nanoparticles; (ii) adsorption of $\mathrm{Hg}^{2+}$ on the surface of AgNPs and their reduction to $\mathrm{Hg}^{0}$ by the surface $\mathrm{Ag}$ atoms (simultaneously obtained $\mathrm{Ag}^{+}$diffuse into the solution); (iii) amalgamation of the freshly generated mercury atoms with the surface $\mathrm{Ag}$ atoms [25, 32, 39]; (iv) the interaction of $\mathrm{Hg}^{2+}$ with AgNPs which decreases surface charges of nanoparticles, leading to their destabilization and aggregation. The latter one is confirmed by the shape evolution of AgNPs observed in Figure 6(a). The suggested mechanism of optical sensing of $\mathrm{Hg}^{2+}$ by starch-coated silver nanoparticles is illustrated in Figure 7.

3.5. Analytical Application. In order to test the applicability of the sensor developed for $\mathrm{Hg}^{2+}$ and total $\mathrm{Hg}$ determination, samples of tap water (Sofia) and mineral water (Gorna Bania, 
TABLE 1: SAED data of AgNPs aggregates formed after exposure of silver nanoparticles to $\mathrm{Hg}^{2+}$ at concentration of $500 \mu \mathrm{g} \mathrm{L} \mathrm{L}^{-1}$ in the presence of $0.005 \mathrm{~mol} \mathrm{~L}^{-1} \mathrm{HNO}_{3}$. $(h k l)_{\mathrm{f}}$ : double electron diffraction effects; SAED interpretation: accuracy $1 \%$.

\begin{tabular}{|c|c|c|c|c|}
\hline$d(\AA)$ & Relative intensity & $\begin{array}{c}\text { Ag } \\
\text { PDF 89-3722 } \\
a=4.0855(1) \AA \\
\text { SG Fm } \overline{3} \mathrm{~m}\end{array}$ & $\begin{array}{c}\mathrm{Ag} \\
\mathrm{PDF} 87-0598 \\
a=2.8862 \AA, \\
c=10.000 \AA \\
\mathrm{P}_{3} / \mathrm{mmc}\end{array}$ & $\begin{array}{c}\mathrm{Ag}_{2} \mathrm{Hg}_{3} \\
\mathrm{PDF} 65-3156 \\
a=10.0506 \AA \\
\text { SG I23 }\end{array}$ \\
\hline 2.438 & s & - & 101 & $(410)_{\mathrm{f}}$ \\
\hline 2.136 & s & - & - & 332 \\
\hline 1.506 & s & - & - & 622 \\
\hline 1.287 & $\mathrm{~s}$ & $(310)_{\mathrm{f}}$ & - & 237 \\
\hline 1.057 & $\mathrm{w}$ & - & 205 & 930 \\
\hline 0.979 & $\mathrm{w}$ & $(410)_{\mathrm{f}}$ & - & 059 \\
\hline
\end{tabular}

s: strong; w: weak.

TABLE 2: Comparison of different methods using silver nanoparticles as a colorimetric sensing probe for $\mathrm{Hg}^{2+}$ determination.

\begin{tabular}{|c|c|c|c|}
\hline Sensing probe & Linear concentration range & Detection limit & Ref. \\
\hline Starch-stabilized AgNPs & $50 \mathrm{nmol} \mathrm{L}^{-1}-5000 \mathrm{nmol} \mathrm{L}^{-1}$ & $25 \mathrm{nmol} \mathrm{L}^{-1}$ & {$[23]$} \\
\hline $\begin{array}{l}\text { Unmodified AgNPs stabilized with } \\
\text { extract of soap-root plant }\end{array}$ & $10-100 \mu \mathrm{mol} \mathrm{L}{ }^{-1}$ & $2.2 \mu \mathrm{mol} \mathrm{L}^{-1}$ & {$[26]$} \\
\hline Gum kondagogu-stabilized AgNPs & $50-500 \mathrm{nmol} \mathrm{L}^{-1}$ & $\begin{array}{l}50 \mathrm{nmol} \mathrm{L}^{-1} \\
(\mathrm{LOQ})\end{array}$ & {$[31]$} \\
\hline Citrate-capped AgNPs & $0.02 \mathrm{nmol} \mathrm{L}^{-1}-0.9 \mu \mathrm{mol} \mathrm{L}^{-1}$ & - & {$[33]$} \\
\hline $\begin{array}{l}\text { 1-Dodecanethiol-capped Ag nanoprisms } \\
\text { upon the presence of iodides }\end{array}$ & $10-4000 \mathrm{nmol} \mathrm{L}^{-1}$ & $3.3 \mathrm{nmol} \mathrm{L}^{-1}$ & {$[40]$} \\
\hline Poly(vinylpyrrolidone)-stabilized AgNPs & $1 \mathrm{nmol} \mathrm{L}^{-1}-30 \mu \mathrm{mol} \mathrm{L}^{-1}$ & $1 \mathrm{nmol} \mathrm{L}^{-1}$ & {$[41]$} \\
\hline $\begin{array}{l}\text { Carrageenan-functionalized } \mathrm{Ag} / \mathrm{AgCl} \\
\mathrm{NPs}\end{array}$ & $1-100 \mu \mathrm{mol} \mathrm{L}^{-1}$ & $1 \mu \mathrm{mol} \mathrm{L}-1$ & {$[42]$} \\
\hline $\begin{array}{l}\text { Starch-coated AgNPs in the presence of } \\
0.005 \mathrm{~mol} \mathrm{~L}^{-1} \mathrm{HNO}_{3}\end{array}$ & $4.5-2500 \mathrm{nmol} \mathrm{L}^{-1}$ & $4.5 \mathrm{nmol} \mathrm{L}^{-1}$ & This work \\
\hline
\end{tabular}

Kniagevo) were spiked at levels close to the permissible limit (drinking water) of $1 \mu \mathrm{g} \mathrm{L}^{-1}$. Total $\mathrm{Hg}$ content in these samples was defined preliminarily by ICP-MS and results for all samples were below $0.05 \mu \mathrm{g} \mathrm{L}^{-1} \mathrm{Hg}$. Recoveries achieved using the described procedure are in the range 93-97\%, thus confirming the possibility of fast $\mathrm{Hg}^{2+}$ screening in drinking waters using the proposed sensor based on starchcoated AgNPs. The limits of detection (LOD) and limits of quantification (LOQ) were evaluated on the basis of repeated analysis of blank (AgNPs). The calculations were based on $3 \sigma$ and $10 \sigma$ criteria using the linear regression equations and slopes of calibration graphs for $\mathrm{Hg}^{2+}$ (Figure 4). The defined values for $\operatorname{LOD}\left(0.9 \mu \mathrm{g} \mathrm{L}^{-1}\right)$ and LOQ $\left(2.7 \mu \mathrm{g} \mathrm{L}^{-1}\right)$ show that the proposed sensor is not suitable for surface water monitoring but might be successfully used for fast on-site control of the quality of sources for drinking water. Within-batch precision strongly depends on the analyte concentration in the measuring solution: $9-12 \%$ for $\mathrm{Hg}^{2+}$ in the range $0.9-12.5 \mu \mathrm{g} \mathrm{L}^{-1}$ and $5-9 \%$ for $\mathrm{Hg}^{2+}$ in the range over $25-500 \mu \mathrm{g} \mathrm{L}^{-1}$. Table 2 further summarizes the linear ranges and detection limits of various $\mathrm{Hg}^{2+}$ detection methods based on silver nanoparticles as a colorimetric sensing probe. It is evident that the proposed method ensures higher or equal sensitivity with those of earlier reported colorimetric AgNPsbased sensors [23, 26, 31, 33, 40-42].

For partial validation of the procedure, CRM Estuarine Water BCR505 was analyzed after solid phase extraction (10fold $\mathrm{Hg}$ enrichment) [43]. Three sample aliquots of $800 \mu \mathrm{L}$ were analyzed according to the proposed analytical procedure. The result of $0.73 \pm 0.08 \mathrm{nmol} \mathrm{L}^{-1} \mathrm{Hg}$ was in reasonable agreement with the (additional material information) value of $0.69 \mathrm{nmol} \mathrm{kg}^{-1} \mathrm{Hg}\left(138 \mu \mathrm{g} \mathrm{L}^{-1}\right)$.

\section{Conclusions}

A simple, fast, and low cost analytical procedure is developed for easy and sensitive quantification of $\mathrm{Hg}^{2+}$ in the presence of $0.005 \mathrm{~mol} \mathrm{~L}^{-1} \mathrm{HNO}_{3}$ by using starch-coated AgNPs as a LSPR-based optical sensor. The $\mathrm{Hg}^{2+}$ sensing is based on the optical response (change in the absorbance strength of LSPR band) of silver nanoparticles depending on the $\mathrm{Hg}^{2+}$ concentration. Possible mechanism of interaction between 
AgNPs and $\mathrm{Hg}^{2+}$ was proposed. An accurate and reliable determination of $\mathrm{Hg}$ is achieved in two concentration ranges: $0.9-12.5 \mu \mathrm{g} \mathrm{L}^{-1}$ and $25-500 \mu \mathrm{g} \mathrm{L}^{-1}$. The limits of detection and quantification achieved were $0.9 \mu \mathrm{g} \mathrm{L}^{-1}$ and $2.7 \mu \mathrm{g} \mathrm{L}^{-1}$, respectively, and relative standard deviations varied in the range $9-12 \%$ for $\mathrm{Hg}$ content from 0.9 to $12.5 \mu \mathrm{g} \mathrm{L}^{-1}$ and $5-9 \%$ for $\mathrm{Hg}$ levels from 25 to $500 \mu \mathrm{g} \mathrm{L}^{-1}$. The LSPR-based optical sensor for $\mathrm{Hg}(\mathrm{II})$ might be used for simple and fast on-site screening of sources for abstraction of drinking water and for $\mathrm{Hg}$ determination in wastewaters.

\section{Conflicts of Interest}

The authors declare that there are no conflicts of interest regarding the publication of this paper.

\section{Acknowledgments}

The authors acknowledge the support by the Horizon 2020 program of the European Commission (project Materials Networking).

\section{References}

[1] D. W. Boening, "Ecological effects, transport, and fate of mercury: a general review," Chemosphere, vol. 40, no. 12, pp. 1335-1351, 2000.

[2] P. Holmes, K. A. F. James, and L. S. Levy, "Is low-level environmental mercury exposure of concern to human health?" Science of the Total Environment, vol. 408, no. 2, pp. 171-182, 2009.

[3] H. Erxleben and J. Ruzicka, "Atomic absorption spectroscopy for mercury, automated by sequential injection and miniaturized in lab-on-valve system," Analytical Chemistry, vol. 77, no. 16, pp. 5124-5128, 2005.

[4] L.-P. Yu and X.-P. Yan, "Flow injection on-line sorption preconcentration coupled with cold vapor atomic fluorescence spectrometry and on-line oxidative elution for the determination of trace mercury in water samples," Atomic Spectroscopy, vol. 25, no. 3, pp. 145-153, 2004.

[5] M. J. Bloxham, S. J. Hill, and P. J. Worsfold, "Determination of mercury in filtered sea-water by flow injection with on-line oxidation and atomic fluorescence spectrometric detection," Journal of Analytical Atomic Spectrometry, vol. 11, no. 7, pp. 511514, 1996.

[6] M. Lombardo, I. Vassura, D. Fabbri, and C. Trombini, "A strikingly fast route to methylmercury acetylides as a new opportunity for monomethylmercury detection," Journal of Organometallic Chemistry, vol. 690, no. 3, pp. 588-593, 2005.

[7] L. Liu, Y.-W. Lam, and W.-Y. Wong, "Complexation of 4,4'di(tert-butyl)-5-ethynyl-2,2' -bithiazole with mercury(II) ion: synthesis, structures and analytical applications," Journal of Organometallic Chemistry, vol. 691, no. 6, pp. 1092-1100, 2006.

[8] A. Caballero, R. Martínez, V. Lloveras et al., "Highly selective chromogenic and redox or fluorescent sensors of $\mathrm{Hg}^{2+}$ in aqueous environment based on 1,4-disubstituted azines," Journal of the American Chemical Society, vol. 127, no. 45, pp. 15666-15667, 2005.

[9] H. Zheng, Z.-H. Qian, L. Xu, F.-F. Yuan, L.-D. Lan, and J.$\mathrm{G}$. $\mathrm{Xu}$, "Switching the recognition preference of rhodamine $\mathrm{B}$ spirolactam by replacing one atom: design of rhodamine B thiohydrazide for recognition of $\mathrm{Hg}(\mathrm{II})$ in aqueous solution," Organic Letters, vol. 8, no. 5, pp. 859-861, 2006.

[10] Y. Zhao and Z. Zhong, "Tuning the sensitivity of a foldamerbased mercury sensor by its folding energy," Journal of the American Chemical Society, vol. 128, no. 31, pp. 9988-9989, 2006.

[11] H. Wang, Y. Wang, J. Jin, and R. Yang, "Gold nanoparticle-based colorimetric and "turn-on" fluorescent probe for mercury(II) ions in aqueous solution," Analytical Chemistry, vol. 80, no. 23, pp. 9021-9028, 2008.

[12] X. Liu, Y. Tang, L. Wang et al., "Optical detection of mercury(II) in aqueous solutions by using conjugated polymers and labelfree oligonucleotides," Advanced Materials, vol. 19, no. 11, pp. 1471-1474, 2007.

[13] I.-B. Kim and U. H. F. Bunz, "Modulating the sensory response of a conjugated polymer by proteins: an agglutination assay for mercury ions in water," Journal of the American Chemical Society, vol. 128, no. 9, pp. 2818-2819, 2006.

[14] S.-J. Liu, H.-G. Nie, J.-H. Jiang, G.-L. Shen, and R.-Q. Yu, "Electrochemical sensor for mercury(II) based on conformational switch mediated by interstrand cooperative coordination," Analytical Chemistry, vol. 81, no. 14, pp. 5724-5730, 2009.

[15] Z. Zhu, Y. Su, J. Li et al., "Highly sensitive electrochemical sensor for mercury(II) ions by using a mercury-specific oligonucleotide probe and gold nanoparticle-based amplification," Analytical Chemistry, vol. 81, no. 18, pp. 7660-7666, 2009.

[16] D. Zhang, M. Deng, L. Xu, Y. Zhou, J. Yuwen, and X. Zhou, “The sensitive and selective optical detection of mercury(II) ions by using a phosphorothioate DNAzyme strategy," Chemistry-A European Journal, vol. 15, no. 33, pp. 8117-8120, 2009.

[17] M. Hollenstein, C. Hipolito, C. Lam, D. Dietrich, and D. M. Perrin, "A highly selective DNAzyme sensor for mercuric ions," Angewandte Chemie-International Edition, vol. 47, no. 23, pp. 4346-4350, 2008.

[18] M. Rex, F. E. Hernandez, and A. D. Campiglia, "Pushing the limits of mercury sensors with gold nanorods," Analytical Chemistry, vol. 78, no. 2, pp. 445-451, 2006.

[19] Y. Wang, F. Yang, and X. Yang, "Colorimetric detection of mercury(II) ion using unmodified silver nanoparticles and mercury-specific oligonucleotides," ACS Applied Materials and Interfaces, vol. 2, no. 2, pp. 339-342, 2010.

[20] Y.-R. Kim, R. K. Mahajan, J. S. Kim, and H. Kim, "Highly sensitive gold nanoparticle-based colorimetric sensing of mercury(II) through simple ligand exchange reaction in aqueous media," ACS Applied Materials and Interfaces, vol. 2, no. 1, pp. 292-295, 2010

[21] D. V. Talapin, J.-S. Lee, M. V. Kovalenko, and E. V. Shevchenko, "Prospects of colloidal nanocrystals for electronic and optoelectronic applications," Chemical Reviews, vol. 110, no. 1, pp. 389$458,2010$.

[22] Y.-L. Hung, T.-M. Hsiung, Y.-Y. Chen, Y.-F. Huang, and C.-C. Huang, "Colorimetric detection of heavy metal ions using labelfree gold nanoparticles and alkanethiols," The Journal of Physical Chemistry C, vol. 114, no. 39, pp. 16329-16334, 2010.

[23] Y. Fan, Z. Liu, L. Wang, and J. Zhan, "Synthesis of starchstabilized $\mathrm{Ag}$ nanoparticles and $\mathrm{Hg}^{2+}$ recognition in aqueous media," Nanoscale Research Letters, vol. 4, no. 10, pp. 1230-1235, 2009. 
[24] G. V. Ramesh and T. P. Radhakrishnan, "A universal sensor for mercury $\left(\mathrm{Hg}, \mathrm{Hg}^{\mathrm{I}}, \mathrm{Hg}^{\mathrm{II}}\right)$ based on silver nanoparticleembedded polymer thin film," ACS Applied Materials \& Interfaces, vol. 3, pp. 988-994, 2011.

[25] E. Sumesh, M. S. Bootharaju, Anshup, and T. Pradeep, "A practical silver nanoparticle-based adsorbent for the removal of $\mathrm{Hg}^{2+}$ from water," Journal of Hazardous Materials, vol. 189, no. 1-2, pp. 450-457, 2011.

[26] K. Farhadi, M. Forough, R. Molaei, S. Hajizadeh, and A. Rafipour, "Highly selective $\mathrm{Hg}^{2+}$ colorimetric sensor using green synthesized and unmodified silver nanoparticles," Sensors and Actuators B: Chemical, vol. 161, no. 1, pp. 880-885, 2012.

[27] G. Maduraiveeran and R. Ramaraj, "Enhanced sensing of mercuric ions based on dinucleotide-functionalized silver nanoparticles," Analytical Methods, vol. 8, no. 44, pp. 7966-7971, 2016.

[28] A. Jeevika and D. R. Shankaran, "Functionalized silver nanoparticles probe for visual colorimetric sensing of mercury," Materials Research Bulletin, vol. 83, pp. 48-55, 2016.

[29] Y. Ma, Y. Pang, F. Liu, H. Xu, and X. Shen, "Microwave-assisted ultrafast synthesis of silver nanoparticles for detection of $\mathrm{Hg}^{2+}$," Spectrochimica Acta Part A: Molecular and Biomolecular Spectroscopy, vol. 153, pp. 206-211, 2016.

[30] Z. Guo, G. Chen, G. Zeng et al., "Ultrasensitive detection and co-stability of mercury(II) ions based on amalgam formation with Tween 20-stabilized silver nanoparticles," RSC Advances, vol. 4, no. 103, pp. 59275-59283, 2014.

[31] L. Rastogi, R. B. Sashidhar, D. Karunasagar, and J. Arunachalam, "Gum kondagogu reduced/stabilized silver nanoparticles as direct colorimetric sensor for the sensitive detection of $\mathrm{Hg}^{2+}$ in aqueous system," Talanta, vol. 118, pp. 111-117, 2014.

[32] S. S. Ravi, L. R. Christena, N. Saisubramanian, and S. P. Anthony, "Green synthesized silver nanoparticles for selective colorimetric sensing of $\mathrm{Hg}^{2+}$ in aqueous solution at wide $\mathrm{pH}$ range," Analyst, vol. 138, no. 15, pp. 4370-4377, 2013.

[33] G.-L. Wang, X.-Y. Zhu, H.-J. Jiao, Y.-M. Dong, and Z.-J. Li, "Ultrasensitive and dual functional colorimetric sensors for mercury (II) ions and hydrogen peroxide based on catalytic reduction property of silver nanoparticles," Biosensors and Bioelectronics, vol. 31, no. 1, pp. 337-342, 2012.

[34] P. Vasileva, B. Donkova, I. Karadjova, and C. Dushkin, "Synthesis of starch-stabilized silver nanoparticles and their application as a surface plasmon resonance-based sensor of hydrogen peroxide," Colloids and Surfaces A: Physicochemical and Engineering Aspects, vol. 382, no. 1-3, pp. 203-210, 2011.

[35] P. Mulvaney, "Surface plasmon spectroscopy of nanosized metal particles," Langmuir, vol. 12, no. 3, pp. 788-800, 1996.

[36] T. Morris, H. Copeland, E. McLinden, S. Wilson, and G. Szulczewski, "The effects of mercury adsorption on the optical response of size-selected gold and silver nanoparticles," Langmuir, vol. 18, no. 20, pp. 7261-7264, 2002.

[37] S. Komulainen, J. Pursiainen, P. Perämäki, and M. Lajunen, "Complexation of $\mathrm{Fe}(\mathrm{III})$ with water-soluble oxidized starch," Starch, vol. 65, no. 3-4, pp. 338-345, 2013.

[38] K. P. Lisha, Anshup, and T. Pradeep, "Towards a practical solution for removing inorganic mercury from drinking water using gold nanoparticles," Gold Bulletin, vol. 42, no. 2, pp. 144$152,2009$.

[39] S. Manivannan and R. Ramaraj, "Silver nanoparticles embedded in cyclodextrin-silicate composite and their applications in $\mathrm{Hg}(\mathrm{II})$ ion and nitrobenzene sensing," Analyst, vol. 138, no. 6, pp. 1733-1739, 2013.
[40] L. Chen, X. Fu, W. Lu, and L. Chen, "Highly sensitive and selective colorimetric sensing of $\mathrm{Hg}^{2+}$ based on the morphology transition of silver nanoprisms," ACS Applied Materials and Interfaces, vol. 5, no. 2, pp. 284-290, 2013.

[41] L. Li, L. Gui, and W. Li, "A colorimetric silver nanoparticlebased assay for $\mathrm{Hg}(\mathrm{II})$ using lysine as a particle-linking reagent," Microchimica Acta, vol. 182, no. 11-12, pp. 1977-1981, 2015.

[42] K. B. Narayanan and S. S. Han, "Highly selective and quantitative colorimetric detection of mercury(II) ions by carrageenanfunctionalized Ag/AgCl nanoparticles," Carbohydrate Polymers, vol. 160, pp. 90-96, 2017.

[43] E. K. Mladenova, I. G. Dakova, D. L. Tsalev, and I. B. Karadjova, "Mercury determination and speciation analysis in surface waters," Central European Journal of Chemistry, vol. 10, no. 4, pp. 1175-1182, 2012. 

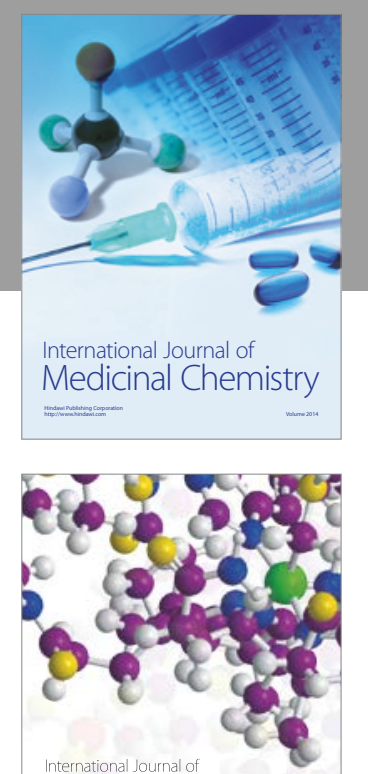

Carbohydrate Chemistry

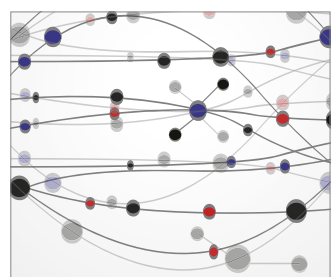

The Scientific World Journal
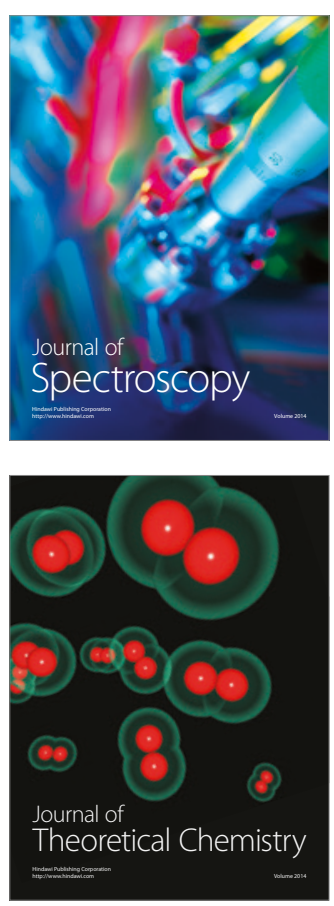
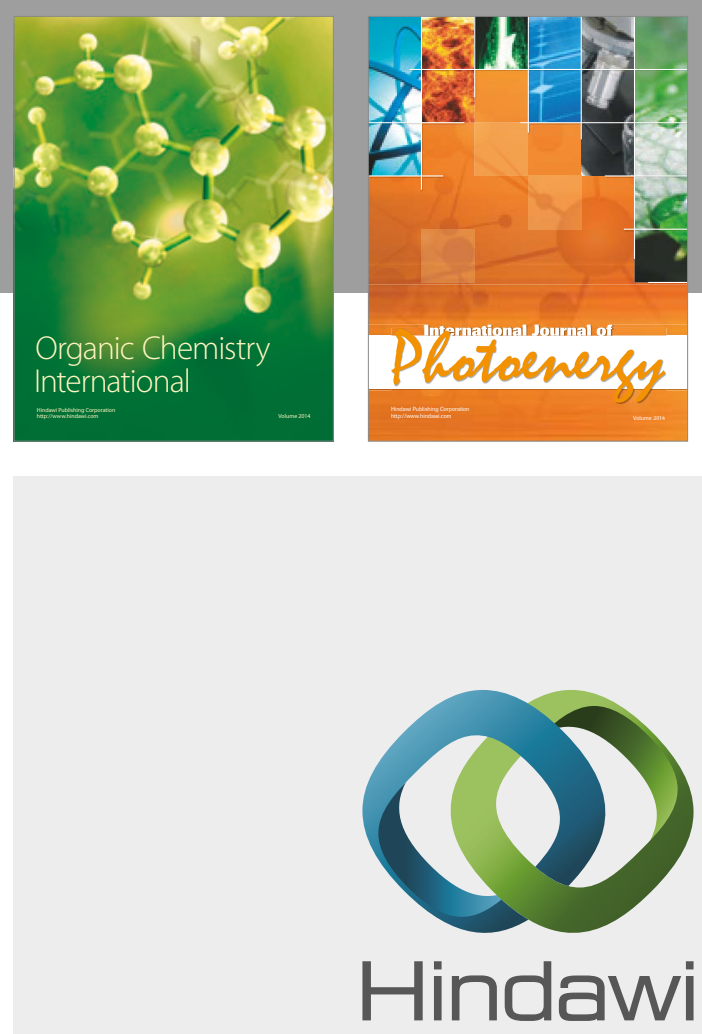

Submit your manuscripts at

https://www.hindawi.com

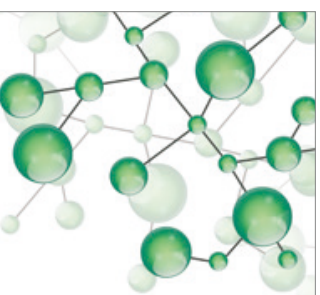

International Journal of

Inorganic Chemistry

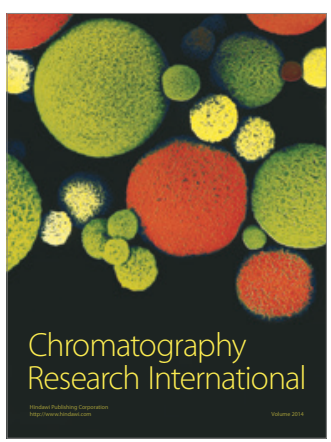

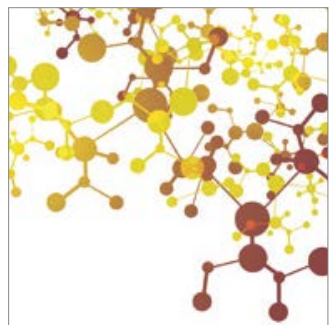

Applied Chemistry
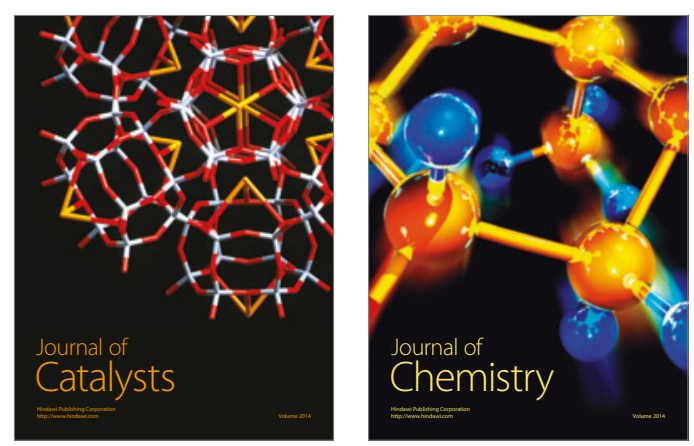
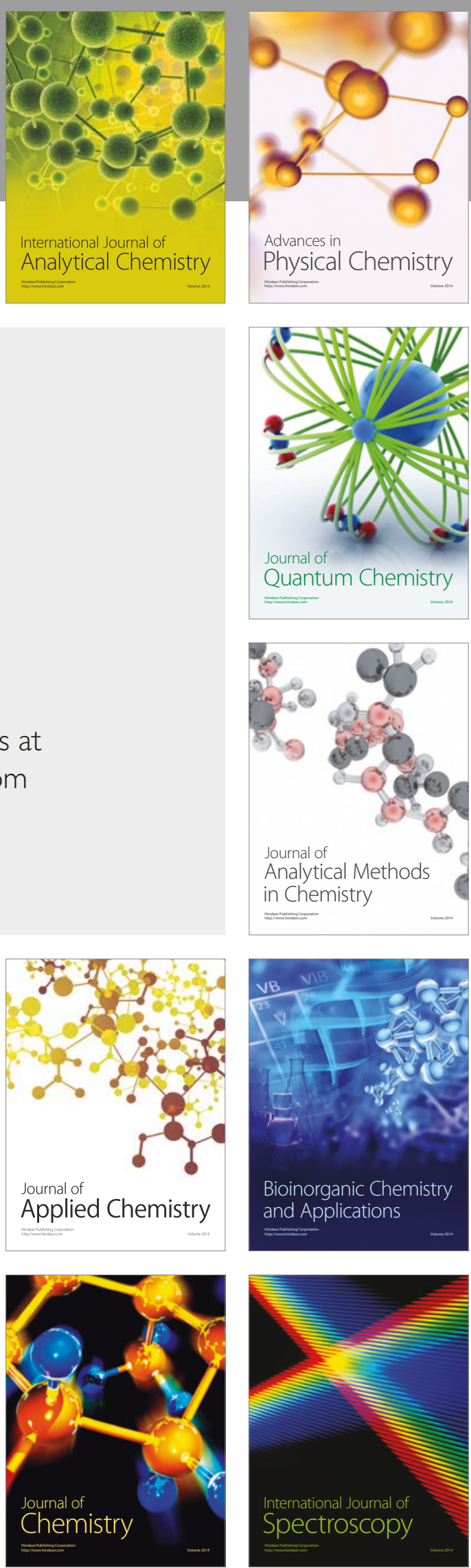